\title{
Estimation of Maneuverability of Trawl Fishing Vessel Using an Analytical Method
}

\author{
Su-Hyung Kim ${ }^{1}(\mathbb{D})$ and Chun-Ki Lee ${ }^{2, *}$ \\ 1 Training Ship, Pukyong National University, Busan 48513, Korea; prodoll1@naver.com \\ 2 Division of Navigation Convergence Studies, Korea Maritime and Ocean University, Busan 49112, Korea \\ * Correspondence: leeck@kmou.ac.kr
}

check for updates

Citation: Kim, S.-H.; Lee, C.-K. Estimation of Maneuverability of Trawl Fishing Vessel Using an Analytical Method. J. Mar. Sci. Eng. 2021, 9, 854. https://doi.org/ $10.3390 /$ jmse9080854

Academic Editors: Zaojian Zou and Tieshan Li

Received: 26 July 2021

Accepted: 7 August 2021

Published: 8 August 2021

Publisher's Note: MDPI stays neutral with regard to jurisdictional claims in published maps and institutional affiliations.

Copyright: (c) 2021 by the authors. Licensee MDPI, Basel, Switzerland. This article is an open access article distributed under the terms and conditions of the Creative Commons Attribution (CC BY) license (https:/ / creativecommons.org/licenses/by/ $4.0 /)$.

\begin{abstract}
Most fishing vessels are less than $100 \mathrm{~m}$ in length between the perpendiculars, for which adherence to the International Maritime Organization maneuverability standards are not mandatory. In the design stage of fishing vessels, maneuverability is estimated using empirical formulas-mainly analytical methods-rather than costly and time-consuming model tests. However, the empirical formula is developed through the process of regression analysis on the model test results from merchant ships' hull form and applying the same to the fishing vessels' hull form may result in an estimation error due to the differences in the vessels' characteristics-e.g., $\mathrm{L} / \mathrm{B}, \mathrm{B} / \mathrm{d}$ and $\mathrm{C}_{\mathrm{b}} \cdot \mathrm{B} / \mathrm{L}-$. In a previous study, the authors of this paper derived a modified empirical formula by adding the hull form parameters of trawl fishing vessels to the existing empirical formula based on those of merchant ships. This study analyzes the validity of the modified empirical formula in depth by applying it to a newly-built training vessel that has the hull form of a trawl fishing vessel. As a result of the study, the estimation results were improved by including the parameters of the hull form of trawl fishing vessels in the empirical formula developed for merchant ships.
\end{abstract}

Keywords: maneuverability; empirical formulas; fishing vessel hull form parameters; trawl fishing vessels

\section{Introduction}

In 2002, the International Maritime Organization (IMO) approved maneuverability standards that should be applied to all ships that are $100 \mathrm{~m}$ in length between the perpendiculars or longer of all rudder and propulsion types, and to chemical tankers, and gas carriers, regardless of their length [1]. The establishment of these standards accelerated research on accurate estimation of the maneuverability of a ship in the design stage. However, since most fishing vessels are less than $100 \mathrm{~m}$ in LBP, the IMO maneuverability standards do not apply [1]. Therefore, studies on maneuverability are usually conducted only for specific vessels. Studies performed by Yoshimura [2,3], Dan [4], Lee [5-7], and Kim [8] are representative of those that estimate maneuverability in vessels less than $100 \mathrm{~m}$ in LBP but are insufficiently compared to studies on merchant ships' hull form.

Methods for estimating maneuverability in the design stage may utilize model tests, similar/equivalent hull forms from the past, or numerical methods [9]. The maneuverability of fishing vessels is estimated by adopting an empirical formula that derives results through a simple process rather than a costly and time-consuming model test (despite the high accuracy of those model tests) [10]. However, the empirical formula currently used is generally derived from the model test results of merchant ship's hull form with the length of $100 \mathrm{~m}$ or longer to which the IMO maneuverability standard is applied. Since several parameters such as $\mathrm{L} / \mathrm{B}$ and $\mathrm{C}_{\mathrm{b}} \cdot \mathrm{B} / \mathrm{L}$-where $\mathrm{L}, \mathrm{B}, \mathrm{C}_{\mathrm{b}}$ stand for the LBP, breadth, and block coefficient of the hull, respectively-are highly correlated with one another during the derivation process, the accuracy of estimation, however, may vary depending on the similarity of hull forms between the target ship and merchant ships [10,11]. 
Fishing vessels have its own hull form characteristics that are somewhat different from those of general merchant ships because they must have the mobility to chase moving fish groups, high volume of fish tanks, and the stability to stay upright. Therefore, when the empirical formula developed for merchant ships' hull form is applied to fishing vessels without correction, estimation errors may occur due to the different characteristics of hull forms [10].

Although maritime accidents caused by fishing vessels do not causes enormous natural disasters compared with those caused by large merchant ships, they can still result in enormous casualties as fishing activities require multiple people on board. Regardless of whether the IMO maneuverability standards are applied or not, researchers should continuously conduct studies to estimate the maneuverability of fishing vessels to provide the motion characteristic indices to the ship operators. In addition, it is necessary to develop a simulation program for accident analysis when maritime accidents occur due to maneuverability [12-15].

In this context, the authors of this paper previously estimated the maneuverability of trawl fishing vessels' hull form using Kijima et al. (1990) empirical formula [16]. To improve estimation accuracy, a modified empirical formula was also derived by adding the hull form parameters of the trawl fishing vessels. In this paper, we use Kijima et al. (1990) empirical formula and our modified empirical formula to perform turning motion and zigzag test simulations, which constitute part of the IMO maneuverability assessment on a training vessel with a trawl fishing vessel's hull form built in 2020. Then, the validity of the modified empirical formula is determined by comparing the results of the simulation to those from tests conducted on the actual vessel [17].

\section{Mathematical Model}

\subsection{Coordinate Systems and Equations of Motion}

The equations of motion used in this study were derived from the right-handed Cartesian coordinate system in Figure 1 . The term $\mathrm{o}_{0}-\mathrm{x}_{0} \mathrm{y}_{0} \mathrm{z}_{0}$ represents the earth-fixed coordinate system, and the term o-xyz represents the hull-fixed coordinate system, in which the mid-ship of the hull is fixed at the point of origin (o). Here $z_{0}$ is oriented vertically downwards in the $x_{0}-y_{0}$ plane, and $z$ is oriented vertically downwards in the $\mathrm{x}-\mathrm{y}$ plane.

There are several ways to express the equation of motion for maneuvering, but in Kijima et al. (1990) empirical formula (used as the reference model for this study), the drift angle $\beta$ and the dimensionless angular velocity $\mathrm{r}^{\prime}$ were used to express maneuverability as shown in Equation (1):

$$
\left.\begin{array}{c}
\left(\mathrm{m}^{\prime}+\mathrm{m}_{\mathrm{x}}^{\prime}\right)\left(\frac{\mathrm{L}}{\mathrm{U}}\right)\left(\frac{\dot{\mathrm{U}}}{\mathrm{U}} \cos \beta-\dot{\beta} \sin \beta\right)+\left(\mathrm{m}^{\prime}+\mathrm{m}_{\mathrm{y}}^{\prime}\right) \mathrm{r}^{\prime} \sin \beta=\mathrm{X}^{\prime} \\
-\left(\mathrm{m}^{\prime}+\mathrm{m}_{\mathrm{y}}^{\prime}\right)\left(\frac{\mathrm{L}}{\mathrm{U}}\right)(\dot{\mathrm{U}} \operatorname{U} \sin \beta+\dot{\beta} \cos \beta)+\left(\mathrm{m}^{\prime}+\mathrm{m}_{\mathrm{x}}^{\prime}\right) \mathrm{r}^{\prime} \cos \beta=\mathrm{Y}^{\prime} \\
\left(\mathrm{I}_{\mathrm{zz}}^{\prime}+\mathrm{i}_{\mathrm{zz}}^{\prime}\right)\left(\frac{\mathrm{L}}{\mathrm{U}}\right)^{2}\left(\frac{\dot{\mathrm{U}}}{\mathrm{L}} \mathrm{r}^{\prime}+\frac{\mathrm{U}}{\mathrm{L}} \dot{\mathrm{r}}^{\prime}\right)=\mathrm{N}^{\prime}
\end{array}\right\}
$$

Here, ' (prime) represents a quantity that is rendered dimensionless as shown below.

$$
\begin{gathered}
\mathrm{m}^{\prime}, \mathrm{m}_{\mathrm{x}}^{\prime}, \mathrm{m}_{\mathrm{y}}^{\prime}=\mathrm{m}, \mathrm{m}_{\mathrm{x}}, \mathrm{m}_{\mathrm{y}} / \frac{1}{2} \rho \mathrm{L}^{2} \mathrm{~d} \\
\mathrm{I}_{\mathrm{zz}}^{\prime} \mathrm{i}_{\mathrm{zz}}^{\prime}=\mathrm{I}_{\mathrm{zz}}, \mathrm{i}_{\mathrm{zz}} / \frac{1}{2} \rho \mathrm{L}^{4} \mathrm{~d} \\
\mathrm{X}^{\prime}, \mathrm{Y}^{\prime}=\mathrm{X}, \mathrm{Y} / \frac{1}{2} \rho \mathrm{LdU}^{2} \mathrm{~N}^{\prime}=\mathrm{N} / \frac{1}{2} \rho \mathrm{L}^{2} \mathrm{dU}^{2} \\
\mathrm{r}^{\prime}=\mathrm{rL} / \mathrm{U}
\end{gathered}
$$

Kijima et al. (1990) empirical formula was based on the maneuvering modeling group model $[9,18]$. Equation (1) can be expressed as Equation (2) by dividing the external force terms $X^{\prime}, Y^{\prime}$, and $N^{\prime}$ on the right side into the hull, rudder, and propeller compo- 
nents, respectively. Here, the subscripts $\mathrm{H}, \mathrm{R}$, and $\mathrm{P}$ denote hull, rudder, and propeller, respectively [16].

$$
\left.\begin{array}{c}
\mathrm{X}^{\prime}=\mathrm{X}_{\mathrm{H}}^{\prime}+\mathrm{X}_{\mathrm{R}}^{\prime}+\mathrm{X}_{\mathrm{P}}^{\prime} \\
\mathrm{Y}^{\prime}=\mathrm{Y}_{\mathrm{H}}^{\prime}+\mathrm{Y}_{\mathrm{R}}^{\prime} \\
\mathrm{N}^{\prime}=\mathrm{N}_{\mathrm{H}}^{\prime}+\mathrm{N}_{\mathrm{R}}^{\prime}
\end{array}\right\}
$$

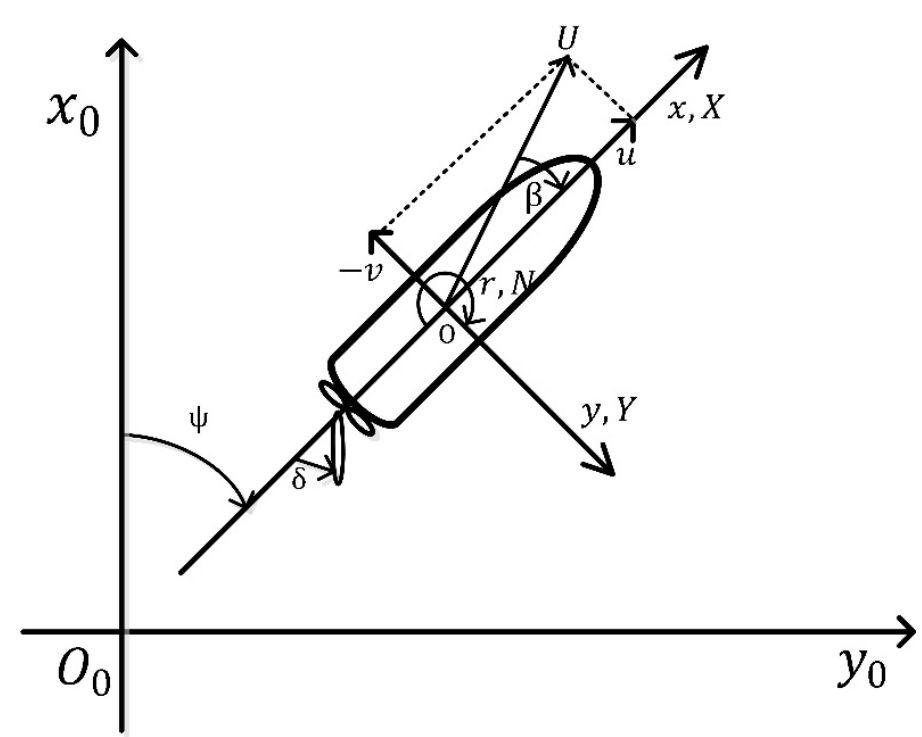

Figure 1. Coordinate system.

\subsubsection{Forces and Moments Acting on the Hull}

The forces $X_{H}^{\prime}$ and $Y_{H}^{\prime}$ and the moment $N_{H}^{\prime}$ acting on the hull can be expressed as Equation (3), using the drift angle, $\beta$, and the dimensionless angular velocity, $\mathrm{r}^{\prime}$, [19].

$$
\left.\begin{array}{c}
\mathrm{X}_{\mathrm{H}}^{\prime}=\mathrm{X}_{\beta \mathrm{r}}^{\prime} \mathrm{r}^{\prime} \sin \beta+\mathrm{X}_{\mathrm{uu}}^{\prime} \cos ^{2} \beta \\
\mathrm{Y}_{\mathrm{H}}^{\prime}=\mathrm{Y}_{\beta}^{\prime} \beta+\mathrm{Y}_{\mathrm{r}}^{\prime} \mathrm{r}^{\prime}+\mathrm{Y}_{\beta \beta}^{\prime} \beta|\beta|+\mathrm{Y}_{\mathrm{rr}}^{\prime} \mathrm{r}^{\prime}\left|\mathrm{r}^{\prime}\right|+\left(\mathrm{Y}_{\beta \beta \mathrm{r}}^{\prime} \beta+\mathrm{Y}_{\beta \mathrm{rr}}^{\prime} \mathrm{r}^{\prime}\right) \beta \mathrm{r}^{\prime} \\
\mathrm{N}_{\mathrm{H}}^{\prime}=\mathrm{N}_{\beta}^{\prime} \beta+\mathrm{N}_{\mathrm{r}}^{\prime} \mathrm{r}^{\prime}+\mathrm{N}_{\beta \beta}^{\prime} \beta|\beta|+\mathrm{N}_{\mathrm{rr}}^{\prime} \mathrm{r}^{\prime}\left|\mathrm{r}^{\prime}\right|+\left(\mathrm{N}_{\beta \beta \mathrm{r}}^{\prime} \beta+\mathrm{N}_{\beta \mathrm{rr}}^{\prime} \mathrm{r}^{\prime}\right) \beta \mathrm{r}^{\prime}
\end{array}\right\}
$$

\subsubsection{Forces and Moments from the Propellers}

In general, the force generated from the propeller is the forward and backward force, $X_{P}^{\prime}$. If terms $Y_{P}^{\prime}$ and $N_{P}^{\prime}$ are omitted on the assumption that force $Y_{p}^{\prime}$ and moment $N_{p}^{\prime}$ are negligible, it can be expressed as Equation (4) as follows [16].

$$
\left.\begin{array}{c}
X_{P}^{\prime}=C_{t_{P}}\left(1-t_{P 0}\right) K_{T}\left(J_{P}\right) n^{2} D_{P}^{4} / \frac{1}{2} L_{d U^{2}} \\
K_{T}\left(J_{P}\right)=C_{1}+C_{2} J_{P}+C_{3} J_{P}^{2} \\
J_{P}=U \cos \beta\left(1-w_{P}\right) /\left(n D_{P}\right)
\end{array}\right\}
$$

\subsubsection{Forces and Moments from the Rudder}

Forces $X_{R}^{\prime}$ and $Y_{R}^{\prime}$ and moment $N_{R}^{\prime}$ from the rudder are given by Equation (5), where $t_{R}, a_{H}$, and $x_{H}^{\prime}$ are the main interaction coefficients acting between the rudder, propeller, and hull, and the normal pressure $\mathrm{F}_{\mathrm{N}}^{\prime}$ has high correlation with the interaction coefficients [16].

$$
\left.\begin{array}{c}
\mathrm{X}_{\mathrm{R}}^{\prime}=-\left(1-\mathrm{t}_{\mathrm{R}}\right) \mathrm{F}_{\mathrm{N}}^{\prime} \sin \delta \\
\mathrm{Y}_{\mathrm{R}}^{\prime}=-\left(1+\mathrm{a}_{\mathrm{H}}\right) \mathrm{F}_{\mathrm{N}}^{\prime} \cos \delta \\
\mathrm{N}_{\mathrm{R}}^{\prime}=-\left(\mathrm{x}_{\mathrm{R}}^{\prime}+\mathrm{a}_{\mathrm{H}} \mathrm{x}_{\mathrm{H}}^{\prime}\right) \mathrm{F}_{\mathrm{N}}^{\prime} \cos \delta
\end{array}\right\}
$$




$$
\begin{gathered}
\mathrm{F}_{\mathrm{N}}^{\prime}=\left(\mathrm{A}_{\mathrm{R}} / \mathrm{Ld}\right) \mathrm{C}_{\mathrm{N}} \mathrm{U}_{\mathrm{R}}^{\prime 2} \sin \mathrm{a}_{\mathrm{R}} \\
\mathrm{C}_{\mathrm{N}}=6.13 \mathrm{~K}_{\mathrm{R}} /\left(\mathrm{K}_{\mathrm{R}}+2.25\right) \\
\mathrm{U}_{\mathrm{R}}^{\prime 2}=\left(1-\mathrm{w}_{\mathrm{R}}\right)^{2}\{1+\mathrm{Cg}(\mathrm{s})\} \\
\mathrm{g}(\mathrm{s})=\eta \mathrm{K}\{2-(2-\mathrm{K}) \mathrm{s}\} \mathrm{s} /(1-\mathrm{s})^{2} \\
\eta=\mathrm{D}_{\mathrm{P}} / \mathrm{h}_{\mathrm{R}} \\
\mathrm{K}=0.6\left(1-\mathrm{w}_{\mathrm{P}}\right) /\left(1-\mathrm{w}_{\mathrm{R}}\right) \\
\mathrm{s}=1.0-\left(1-\mathrm{w}_{\mathrm{P}}\right) \mathrm{U} \cos \beta / \mathrm{nP} \\
\mathrm{w}_{\mathrm{R}}=\mathrm{w}_{\mathrm{R} 0} \cdot \mathrm{w}_{\mathrm{P}} / \mathrm{w}_{\mathrm{P} 0} \\
\mathrm{a}_{\mathrm{R}}=\delta-\gamma \cdot \beta_{\mathrm{R}}^{\prime} \\
\beta_{\mathrm{R}}^{\prime}=\beta-2 \mathrm{x}_{\mathrm{R}}^{\prime} \cdot \mathrm{r}^{\prime}, \mathrm{x}_{\mathrm{R}}^{\prime} \cong-0.5
\end{gathered}
$$

\subsection{Kijima et al. (1990) Empirical Formula}

Model tests are most likely to minimize the gap between the estimated maneuverability of a ship at the design stage and the actual maneuverability of the constructed ship. However, since fishing vessels relied on the empirical formula rather than model tests, there was a limitation for collecting model test results for fishing vessels to derive an empirical formula tailored to fishing vessels. In light of this, the authors previously conducted a study to modify the empirical formula originally developed for merchant ships' hull form so that it could be applied to fishing-type vessels as well [5-8]. The model empirical formula used for this study was the one proposed by Kijima et al. (1990).

Among numerous empirical formulas developed for merchant ship's hull form, Kijima et al. (1990) empirical formula was selected because the process of deriving the empirical formula and the specifications of the vessels used in the model tests were clearly disclosed. Since the applicable formulas were divided according to whether the shape of the stern was to be considered or not, a wide range of choices were available $[16,20,21]$. However, previous studies confirmed that there were slight differences between the hull form of fishing vessels and that of merchant ships. It was also verified by comparing the simulated trajectories of turning motions that including the shape of the stern as an additional consideration to the equation could reduce the accuracy in estimating the maneuverability of fishing vessels' hull form Therefore, the authors of this study determined that the version of Kijima et al. (1990) empirical formula without considerations for the stern shape is more suitable for estimating the maneuverability of fishing vessels' hull form.

Table 1 shows the main specifications of the 13 model merchant ships used for the derivation of Kijima et al. (1990) empirical formula on an even keel and under full load conditions. Equation (7) displays the equation for deriving the derivatives acting on the hull and the interaction coefficients acting among the hull, propeller, and rudder.

Table 1. Main specifications of model merchant ships (Kijima et al., 1990).

\begin{tabular}{cccccc}
\hline & $\mathbf{L}(\mathbf{m})$ & $\mathbf{B}(\mathbf{m})$ & $\mathbf{d}(\mathbf{m})$ & $\mathbf{C}_{\mathbf{b}}$ & $\mathbf{L} / \mathbf{B}$ \\
\hline A (VLCC) & 2.5 & 0.436 & 0.157 & 0.802 & 5.734 \\
B (VLCC) & 2.5 & 0.408 & 0.170 & 0.831 & 6.127 \\
C (ULCC) & 2.5 & 0.466 & 0.156 & 0.835 & 5.365 \\
D (ULCC) & 2.5 & 0.555 & 0.183 & 0.821 & 4.505 \\
E (ULCC) & 2.5 & 0.500 & 0.183 & 0.820 & 5.000 \\
F (Cargo) & 2.5 & 0.408 & 0.171 & 0.773 & 6.127 \\
G (Cargo) & 2.5 & 0.419 & 0.140 & 0.698 & 5.967 \\
H (Cargo) & 2.5 & 0.376 & 0.158 & 0.651 & 6.649 \\
I (Container) & 3.0 & 0.435 & 0.163 & 0.572 & 6.897 \\
J (Container) & 2.5 & 0.386 & 0.130 & 0.566 & 6.477 \\
K (RO/RO) & 2.5 & 0.367 & 0.102 & 0.557 & 6.812 \\
L (Car carrier) & 2.5 & 0.482 & 0.134 & 0.522 & 5.187 \\
M (LNG) & 2.5 & 0.409 & 0.100 & 0.714 & 6.112 \\
\hline
\end{tabular}




$$
\begin{gathered}
\mathrm{Y}_{\beta}^{\prime}=\frac{1}{2} \pi k+\frac{1.4 \mathrm{C}_{\mathrm{b}} \mathrm{B}}{\mathrm{L}} \\
\mathrm{Y}_{\beta \beta}^{\prime}=\frac{2.5 \mathrm{~d}\left(1-\mathrm{C}_{\mathrm{b}}\right)}{\mathrm{B}}+0.5 \\
\mathrm{Y}_{\mathrm{r}}^{\prime}-\left(\mathrm{m}^{\prime}+\mathrm{m}_{\mathrm{x}}^{\prime}\right)=-\frac{1.5 \mathrm{C}_{\mathrm{b}} \mathrm{B}}{\mathrm{L}} \\
\mathrm{Y}_{\mathrm{rr}}^{\prime}=\frac{0.343 \mathrm{~d} \mathrm{C}_{\mathrm{b}}}{\mathrm{B}}-0.07 \\
\mathrm{Y}_{\beta \mathrm{rr}}^{\prime}=\frac{5.95 \mathrm{~d}\left(1-\mathrm{C}_{\mathrm{b}}\right)}{\mathrm{B}} \\
\mathrm{Y}_{\beta \beta \mathrm{r}}^{\prime}=\frac{1.5 \mathrm{~d} \mathrm{C}_{\mathrm{b}}}{\mathrm{B}}-0.65 \\
\mathrm{~N}_{\beta}^{\prime}=\mathrm{k} \\
\mathrm{N}_{\beta \beta}^{\prime}=-\frac{0.96 \mathrm{~d}\left(1-\mathrm{C}_{\mathrm{b}}\right)}{\mathrm{B}}+0.066 \\
\mathrm{~N}_{\mathrm{r}}^{\prime}=-0.54 \mathrm{k}+\mathrm{k}^{2} \\
\mathrm{~N}_{\mathrm{rr}}^{\prime}=\frac{0.5 \mathrm{C}_{\mathrm{b}} \mathrm{B}}{\mathrm{L}}-0.09 \\
\mathrm{~N}_{\beta \mathrm{rr}}^{\prime}=-\left(\frac{0.5 \mathrm{~d} \mathrm{C}_{\mathrm{b}}}{\mathrm{B}}-0.05\right) \\
=-\left\{57.5\left(\frac{\mathrm{C}_{\mathrm{b}} \mathrm{B}}{\mathrm{L}}\right)^{2}-\frac{18.4 \mathrm{C}_{\mathrm{b}} \mathrm{B}}{\mathrm{L}}+1.6\right\} \\
\mathrm{N}_{\beta \beta \mathrm{r}}^{\prime}=-\mathrm{t}_{\mathrm{R}}=0.28 \mathrm{C}_{\mathrm{b}}+0.55 \\
\mathrm{a}_{\mathrm{H}}=2.2835 \mathrm{C}_{\mathrm{b}}^{2}-0.833 \mathrm{C}_{\mathrm{b}} \\
\mathrm{x}_{\mathrm{H}}^{\prime}=9.72289 \mathrm{C}_{\mathrm{b}}^{2}-8.243538 \mathrm{C}_{\mathrm{b}}-0.00498539 \\
1-\mathrm{w}_{\mathrm{P} 0}=1.05-0.5 \mathrm{C}_{\mathrm{b}} \\
\gamma=-22.2\left(\mathrm{C}_{\mathrm{b}} \mathrm{B} / \mathrm{L}\right)^{2}+0.02\left(\mathrm{C}_{\mathrm{b}} \mathrm{B} / \mathrm{L}\right)+0.68
\end{gathered}
$$

where $\mathrm{k}=2 \mathrm{~d} / \mathrm{L}$.

Meanwhile, Equation (7) reveals that certain parameters such as L/B and $\mathrm{C}_{\mathrm{b}} \cdot \mathrm{B} / \mathrm{L}$ - indicating the hull form characteristics—can be highly correlated with one another during the regression analysis on the model test results [11]. It can also be seen that these parameters can also affect the derivation of derivative values through empirical formulas. The accuracy of results can be improved if such parameters are similar or equivalent to those obtained from the model merchant ships included in the derivation of empirical formulas.

\subsection{Modified Empirical Formula}

In the process of estimating the maneuverability of a vessel using empirical formulas, the main specifications and hull form characteristics of the vessel may affect the estimation accuracy, as described in Section 2.2. The authors of this paper have already confirmed in a previous study that the hull form of fishing vessels has unique characteristics that are somewhat different from those of the merchant ships' hull form $[8,10]$. To estimate the maneuverability of the fishing vessels' hull form more accurately, a modified empirical formula was derived from Kijima et al. (1990) original empirical formula. This section outlines the process of deriving the modified empirical formula.

\subsubsection{Selection of Hull Forms}

The hull forms of fishing vessels, not unlike those of merchant ships, vary depending on the fishing work types. Among those, a trawl fishing vessel hull form was selected as the basis for this study for deriving the modified empirical formula for the following reasons [10].

First, a typical trawl fishing vessel has a larger size than most fishing vessels and carries as many as 50 or more crew members on board; this increases the risk of a large-scale casualty in case of an accident, and thus, we determined the hull form of trawl fishing vessels to be the priority target of research. In addition, it was easier to collect test results at the design stage for trawler hull forms-on traits such as resistance, self-propulsion, and open water tests on propellers, among others-compared to others; these test results are necessary for conducting research to derive a modified empirical formula. Finally, 
regarding test experiments, the trawler hull form obtained stable results with relatively little influence from external factors; this trait allows for a more reliable comparison with the estimated results using the empirical formulas.

Five training trawl fishing vessels were selected as model fishing vessels for this test. The main specifications of the vessels are shown in Table 2.

Table 2. Main specifications of the five model trawl fishing vessels.

\begin{tabular}{cccccc}
\hline & $\mathbf{L}(\mathbf{m})$ & $\mathbf{B}(\mathbf{m})$ & $\mathbf{d}(\mathbf{m})$ & $\mathbf{C}_{\mathbf{b}}$ & $\mathbf{L} / \mathbf{B}$ \\
\hline $\mathrm{F}(\mathrm{A})$ & 3.0 & 0.576 & 0.211 & 0.607 & 5.208 \\
$\mathrm{~F}(\mathrm{~B})$ & 3.0 & 0.609 & 0.223 & 0.610 & 4.927 \\
$\mathrm{~F}(\mathrm{C})$ & 3.0 & 0.546 & 0.207 & 0.574 & 5.492 \\
$\mathrm{~F}(\mathrm{D})$ & 3.0 & 0.529 & 0.184 & 0.587 & 5.667 \\
$\mathrm{~F}(\mathrm{E})$ & 3.0 & 0.544 & 0.187 & 0.592 & 5.520 \\
\hline
\end{tabular}

\subsubsection{Analysis of Hull form Parameters}

Before deriving maneuvering hydrodynamic derivatives of the model ships (13 model merchant ships, five model trawl fishing vessels), using Kijima et al. (1990) empirical formula, $C_{b}$ for the $L / B$ ratio of the model ships were compared to confirm the difference in characteristics between the hull forms of fishing vessels and merchant ships listed in Tables 1 and 2. Results indicate that the $C_{b}$ of the fishing vessels' hull form, which for mobility to chase fish, was similar to that of fine high-speed slender body ships such as container ships, roll-on/roll-off ships, and car carriers [10]. In comparison, the L/B ratio of fishing vessels' hull form, which for fish storage capacity and stability in the rough sea, resembled that of low-speed full body ships such as very/ultra large crude oil carriers (VLCC/ULCC) [10] (Figure 2).

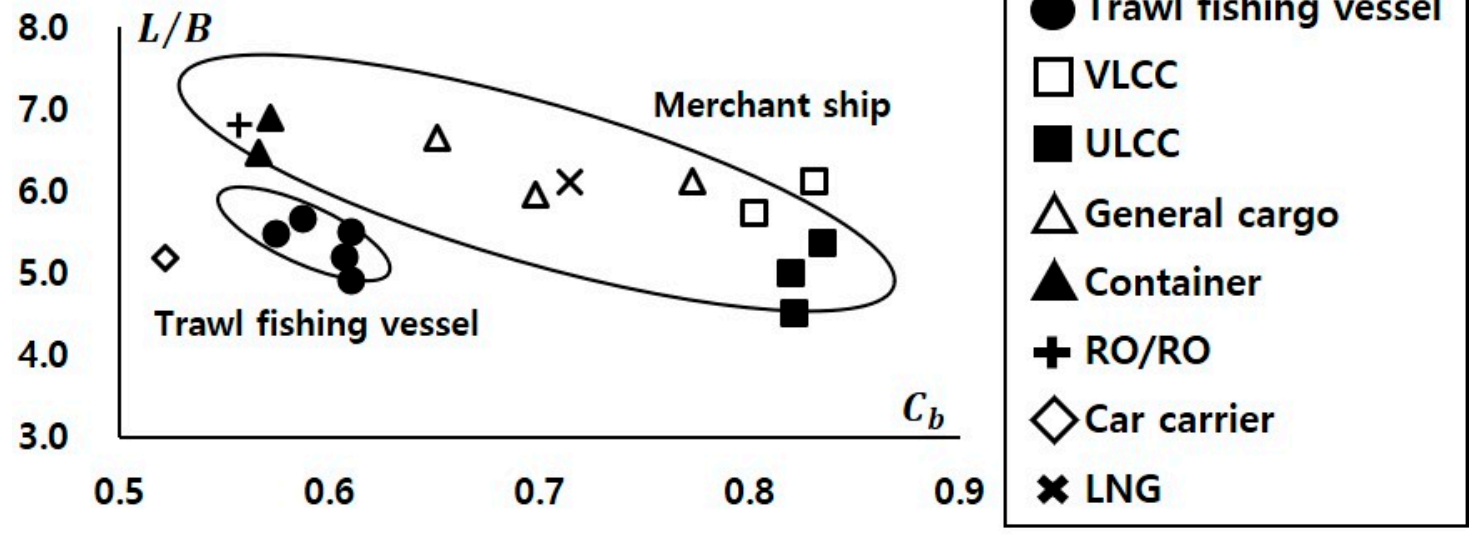

Figure 2. Relationship between $\mathrm{C}_{\mathrm{b}}$ and $\mathrm{L} / \mathrm{B}$ of the model ships.

The $C_{b}$ and $L / B$ presented in Figure 2 are the most representative hull form characteristics that have an important correlation in the model test regression analysis process for deriving empirical expressions. As shown in Figure 2, fishing vessels and merchant ships have somewhat different hull form characteristics. Before deriving the modified empirical formula using Kijima et al. (1990), the major hull form parameter values of the model ships were compared, as shown in Figure 3. First, the $C_{b}$ of model trawl fishing vessels resembled that of container ships the most, and their L/B was similar to that of VLCC, ULCC, and car carriers. In addition, their B/d was comparable to that of several others, such as VLCC, ULCC, cargo ships, and container ships. Lastly, it was confirmed that their $\mathrm{K}(=2 \mathrm{~d} / \mathrm{L})$ was similar to that of VLCC, ULCC. 

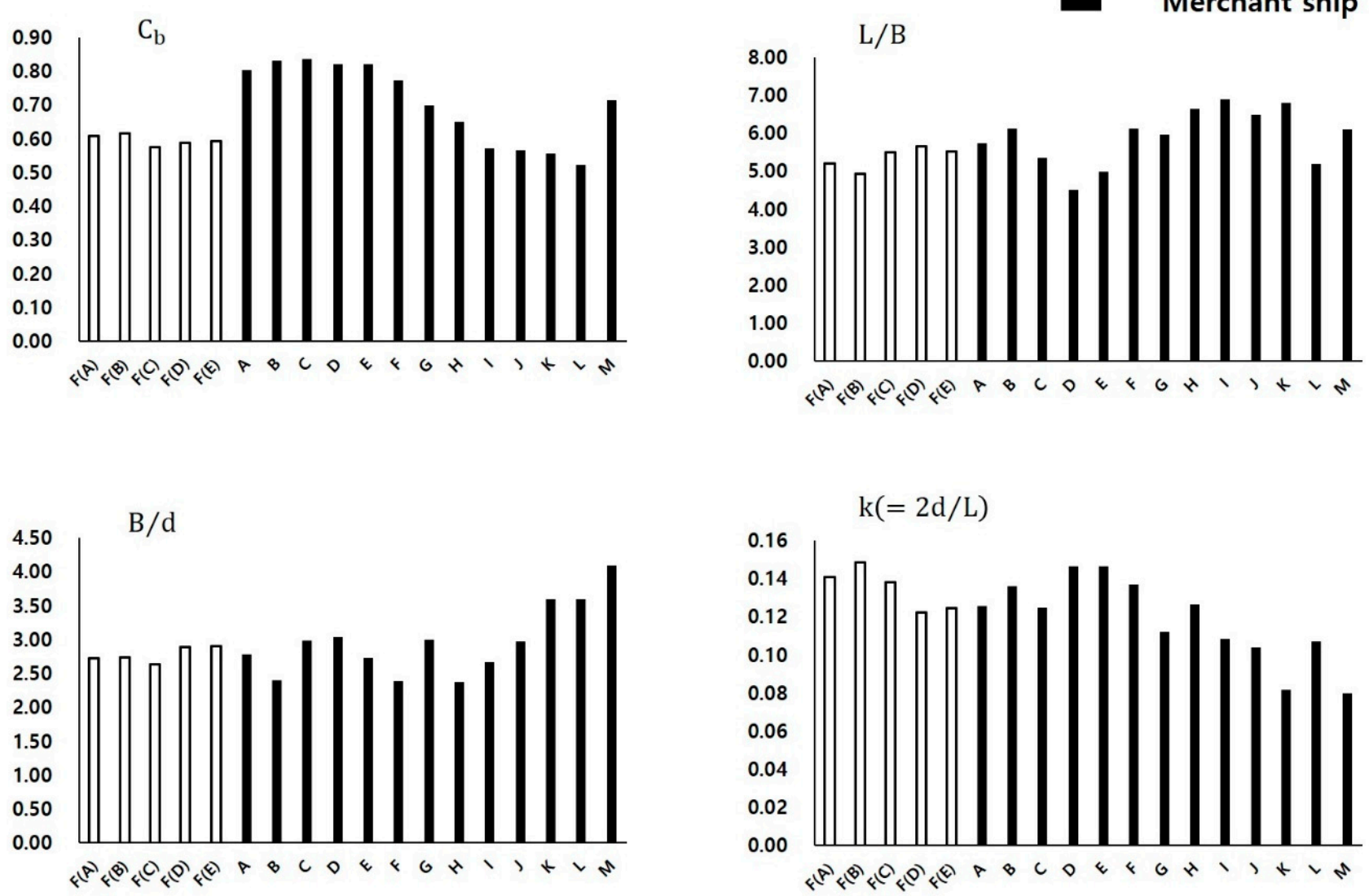

Figure 3. Comparison of the hull form parameters of the model ships.

Figure 3 confirmed that the trawl fishing vessel hull form of model fishing vessels has its own characteristics that are different from those of any specific merchant ship. Results confirmed that an estimation error could occur if the empirical formula developed for merchant ships was applied to fishing vessels without modification.

\subsubsection{Deriving a Modified Empirical Formula}

The most ideal way to develop an empirical formula for estimating the maneuverability of fishing vessels' hull form at the design stage is to go through a research process similar to the one used to develop the empirical formula for merchant ships. However, most of the data on the maneuverability of fishing vessels are studies on a single target vessel, and data for estimating maneuverability such as model tests are lacking [22-26]. Therefore, this study derived a modified empirical formula by adding the hull form parameters of fishing vessels to Kijima et al. (1990) empirical formula originally developed for merchant ships' hull form. The derivation process is outlined below [10], and the modification graph for the linear derivatives is shown in Figure 4. 

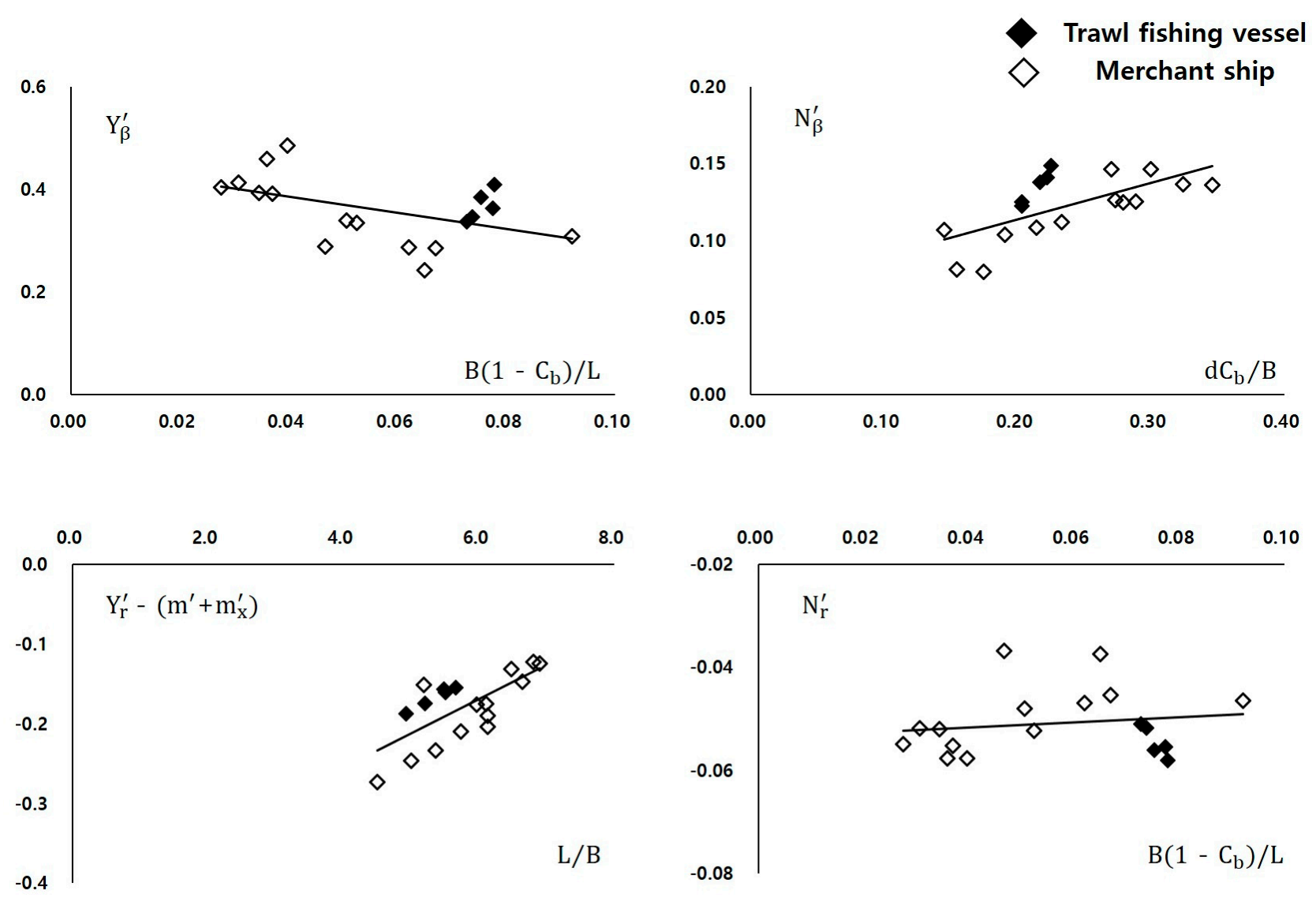

Figure 4. Correlations between linear derivatives and hull form parameters of the model ships.

1. Using Kijima et al. (1990) empirical formula in Equation (7), the maneuvering hydrodynamic derivatives of the 18 model ships (13 model merchant ships, five model trawl fishing vessels) listed in Tables 1 and 2 were derived.

2. In the process of deriving the value of each derivative, all hull form parameters with high correlation with one another were identified.

3. In the preceding step, we identified those parameters (i) which were correlated with each derivative and (ii) whose tendencies differed between the hull forms of fishing vessels and merchant ships; hereafter, we displayed the correlation of the chosen parameters with the derivatives in graphs.

4. The error occurring for the model fishing vessels' hull form was corrected using the average value for the trend line indicated by the graph.

From the results above, a modified empirical formula was derived to improve the estimation of maneuverability for fishing vessels' hull form; the results are shown in Equation (8). However, the modified empirical formula drew a limited set of hull forms from trawl fishing vessels. Therefore, applying the modified empirical formula to other hull forms of fishing vessels may lead to an estimation error due to differences in hull form characteristics.

$$
0.574 \leq \mathrm{C}_{\mathrm{b}} \leq 0.616,4.93 \leq \mathrm{L} / \mathrm{B} \leq 5.67,2.64 \leq \mathrm{B} / \mathrm{d} \leq 2.9
$$




$$
\begin{gathered}
\mathrm{Y}_{\beta}^{\prime}=-1.5747 \times\left\{1-\mathrm{C}_{\mathrm{b}} /(\mathrm{L} / \mathrm{B})\right\}+0.4488 \\
\mathrm{Y}_{\beta \beta}^{\prime}=0.0417 \times(\mathrm{L} / \mathrm{B})+0.541 \\
\mathrm{Y}_{\mathrm{r}}^{\prime}-\left(\mathrm{m}^{\prime}+\mathrm{m}_{\mathrm{x}}^{\prime}\right)=0.0432 \times(\mathrm{L} / \mathrm{B})-0.4276 \\
\mathrm{Y}_{\mathrm{rr}}^{\prime}=-0.7946 \times\left\{1-\mathrm{C}_{\mathrm{b}} /(\mathrm{L} / \mathrm{B})\right\}+0.0563 \\
\mathrm{Y}_{\beta \mathrm{rr}}^{\prime}=0.0993 \times(\mathrm{L} / \mathrm{B})+0.0975 \\
\mathrm{Y}_{\beta \beta \mathrm{r}}^{\prime}=2.7467 \times \mathrm{k}-0.6316 \\
\mathrm{~N}_{\beta}^{\prime}=0.238 \times \mathrm{C}_{\mathrm{b}} /(\mathrm{B} / \mathrm{d})+0.0663 \\
\mathrm{~N}_{\beta \beta}^{\prime}=-0.016 \times(\mathrm{L} / \mathrm{B})+0.0503 \\
\mathrm{~N}_{\mathrm{r}}^{\prime}=0.0515 \times\left\{1-\mathrm{C}_{\mathrm{b}} /(\mathrm{L} / \mathrm{B})\right\}-0.0537 \\
\mathrm{~N}_{\mathrm{rr}}^{\prime}=-0.0144 \times(\mathrm{L} / \mathrm{B})+0.0525 \\
\mathrm{~N}_{\beta \mathrm{rr}}^{\prime}=-0.9156 \times \mathrm{k}+0.0439 \\
\mathrm{~N}_{\beta \beta \mathrm{r}}^{\prime}=-3.399 \times\left\{1-\mathrm{C}_{\mathrm{b}} /(\mathrm{L} / \mathrm{B})\right\}-0.0737 \\
1-\mathrm{t}_{\mathrm{R}}=-0.0127 \times(\mathrm{L} / \mathrm{B})+0.8122 \\
\mathrm{a}_{\mathrm{H}}=-0.1107 \times(\mathrm{L} / \mathrm{B})+1.1421 \\
\mathrm{x}_{\mathrm{H}}^{\prime}=-0.258 \times(\mathrm{L} / \mathrm{B})+0.4603 \\
1-\mathrm{W}_{\mathrm{P} 0}=0.0227 \times(\mathrm{L} / \mathrm{B})+0.5818 \\
\varepsilon=-1.4308 \times\left\{1-\mathrm{C}_{\mathrm{b}} /(\mathrm{L} / \mathrm{B})\right\}+0.9453 \\
\gamma=0.1608 \times(\mathrm{L} / \mathrm{B})-0.5764
\end{gathered}
$$

\subsubsection{Validation of Modified Empirical Formulas}

Table 3 and Figure 5 show the comparison results of the turning motion simulation and the sea trial test for four of the five model trawl fishing vessels used in the derivation process of the modified empirical formula, excluding vessel $\mathrm{F}(\mathrm{E})$ that was under construction at the time of testing. The numerical values listed in Table 3 represent the average for the vessels $\mathrm{F}(\mathrm{A})$ to $\mathrm{F}(\mathrm{D})$ shown in Figure 5 and the result of the sea trial test that was scaled to " 1 ".

Table 3. Quantitative comparison of the turning motion test results of the model trawl fishing vessels.

\begin{tabular}{cccc}
\hline & Sea Trial Test & Kijima et al. (1990) & Modified Formula \\
\hline Advance & 1 & $1.43(43 \% \uparrow)$ & $0.93(7 \% \downarrow)$ \\
Transfer & 1 & $1.55(55 \% \uparrow)$ & $0.96(4 \% \downarrow)$ \\
Tactical Dia. & 1 & $1.50(50 \% \uparrow)$ & $0.95(5 \% \downarrow)$ \\
\hline Average & 1 & $1.49(49 \% \uparrow)$ & $0.94(6 \% \downarrow)$ \\
\hline
\end{tabular}
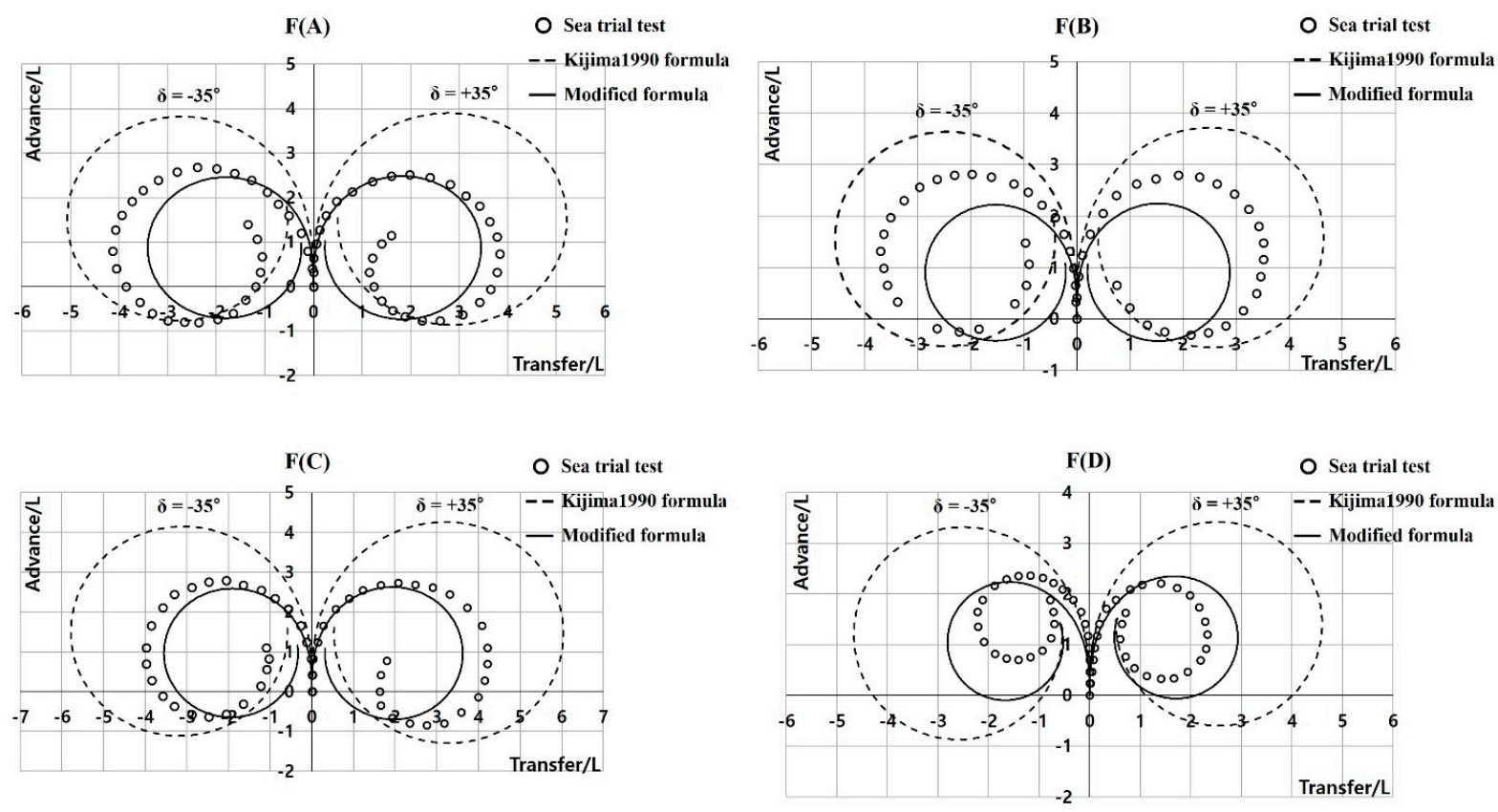

Figure 5. Comparison of the turning motion test results of the model trawl fishing vessels. 
The size of the turning trajectory derived from Kijima et al. (1990) empirical formula was larger than the results from the sea trial test with an average error of $49 \%$. Conversely, the size of the turning trajectory derived from the modified empirical formula was smaller than the sea trial results [except for $F(D)$ ] and showed an average error of $6 \%$. This indicates that the modified empirical formula more closely approximated the results from the sea trial test [10].

\section{Estimation of Trawl Fishing Vessel Maneuverability}

The basic research discussed in Section 2.3.4 confirmed that the modified empirical formula improves results when compared with Kijima et al. (1990) original formula in estimating the maneuverability of trawl fishing vessel hull forms.

In this chapter, the maneuvering hydrodynamic derivatives of the model trawl fishing vessel $F(E)$ are derived, on which the validation study of the modified empirical formula was not performed due to the vessel still being under construction at the time of testing. A maneuverability simulation is performed for the tests included in the IMO maneuverability evaluation list. In addition, an in-depth verification study was conducted to determine the validity of the modified empirical formula by comparing the results with those from the sea trial test.

The basic purpose of this study is to minimize the estimation error that may occur in the design stage of fishing vessels when using the empirical formula meant for merchant ships' hull form. In addition, it is important to check whether the accuracy of estimation can be improved by merely including the hull form parameters of fishing vessels in the empirical formula originally developed for merchant ships' hull form [8].

\subsection{Selection of Target Fishing Vessel}

The target model trawl fishing vessel is vessel $\mathrm{F}(\mathrm{E})$ in Table 2 (hereafter referred to as the target trawler). It is a training vessel that has the hull form of a trawl fishing vessel. The specifications of this vessel was included in the process for deriving the modified empirical formula, but it was excluded from the validation tests using actual ships as it was still under construction at the time. In this study, the validity of the modified empirical formula was verified by conducting in-depth validation studies (turning test, zigzag test, and time history for the target trawler). The main specifications of the target trawler are shown in Table 4, and the body plan and general arrangement are shown in Figure 6.

Table 4. The main specifications of the target trawler.

\begin{tabular}{ccc}
\hline & \multicolumn{2}{c}{ Target Trawler } \\
\hline \multirow{3}{*}{ Hull } & $\mathrm{L}(\mathrm{m})$ & 85.0 \\
& $\mathrm{~B}(\mathrm{~m})$ & 15.4 \\
& $\mathrm{~d}(\mathrm{~m})$ & 5.3 \\
\multirow{2}{*}{ Rudder } & $\mathrm{C}_{\mathrm{b}}$ & 0.592 \\
\hline \multirow{3}{*}{ Propeller } & $\mathrm{A}_{\mathrm{R}}\left(\mathrm{m}^{2}\right)$ & 7.631 \\
& $\delta$ Max. $(\mathrm{deg})$. & 45.0 \\
\hline & Rotation & Right \\
& No. of blades & 4 \\
\hline
\end{tabular}



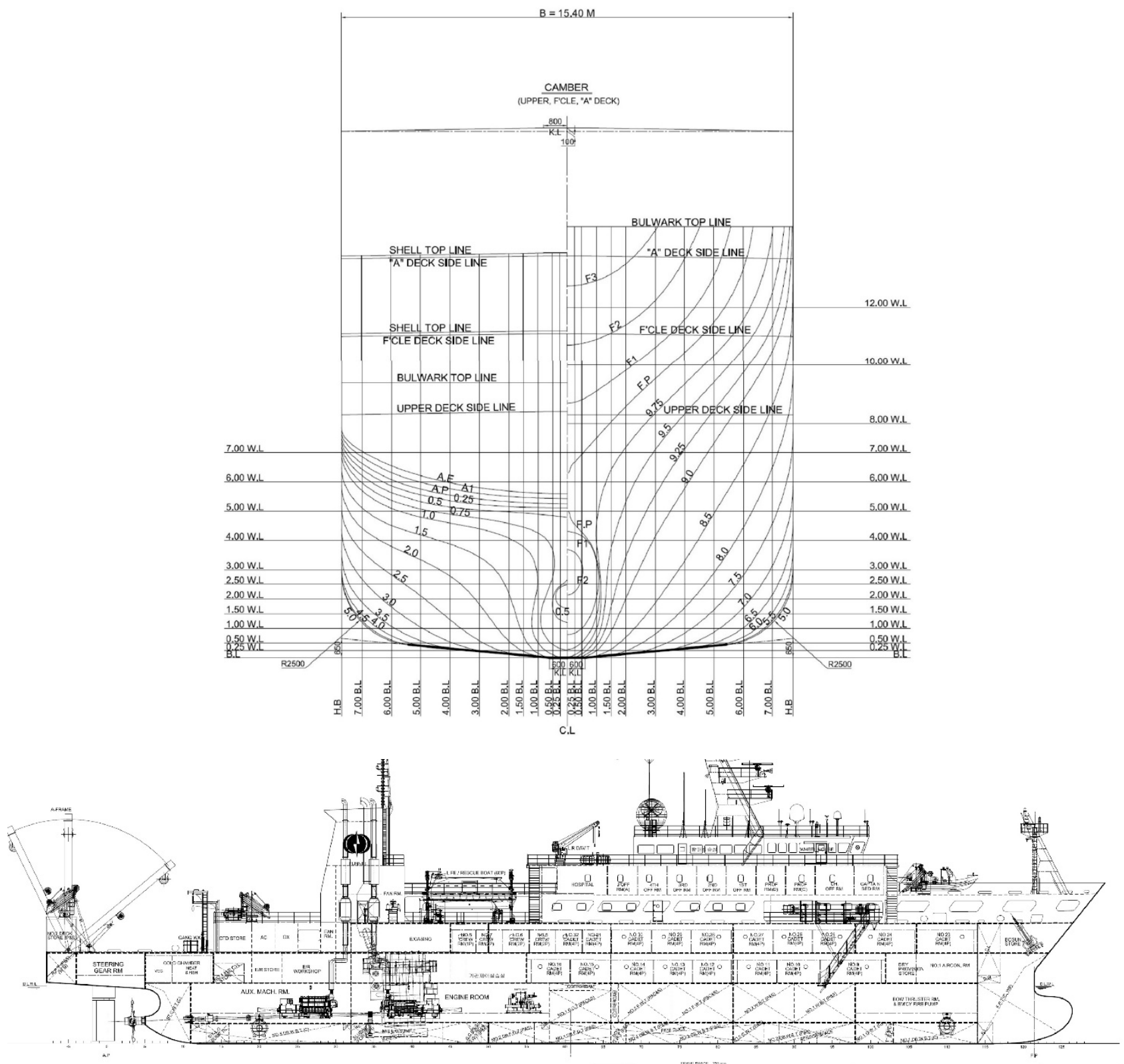

Figure 6. Body plan and general arrangement of the target trawler.

\subsection{Deriving Hydrodynamic Derivatives}

To perform the maneuverability simulation of the target trawler, the hydrodynamic derivatives were derived from Kijima et al. (1990) empirical formula presented in Equation (7) and modified empirical formula presented in Equation (8). The derivatives that are derived from the two empirical formulas can be categorized into the forces and moments acting on the hull and interaction forces acting among the hull, propeller, and rudder. The right-hand sides of Equations (7) and (8) demonstrate that the hydrodynamic derivatives obtained through the empirical formula are affected by hull form parameters. That is, since the empirical formula was developed through the process of regression analysis of the results of the model test, the relative accuracy of estimation may differ depending on the hull form of interest; an accurate estimation can be obtained for hull forms that are similar or equivalent to the ones used in the derivation of empirical formula, whereas the accuracy tends to suffer when applying the formula to a different hull form. In particular, the interaction forces are more difficult to estimate at the design stage because it represents complex hydrodynamic forces occurring among the hull, propeller, and rudder; 
even today, it is estimated by considering the unique characteristics of the same or a similar hull form [16].

However, since the purpose of this study is to verify whether the estimation of the maneuverability of the hull form of fishing vessels can be improved merely by adding the hull form parameters of the fishing vessels to the empirical formula originally developed for merchant ships' hull form, all hydrodynamic derivatives were derived through Equations (7) and (8) with no additional corrections. Table 5 shows the hydrodynamic derivatives of the target trawler [8].

Table 5. The hydrodynamic derivatives of the target trawler.

\begin{tabular}{cccc}
\hline & $\begin{array}{c}\text { Hydrodynamic } \\
\text { Derivatives }\end{array}$ & $\begin{array}{c}\text { Kijima et al.(1990) } \\
\text { Formula }\end{array}$ & Modified Formula \\
\hline \multirow{6}{*}{ Hull } & $\mathrm{Y}_{\beta}^{\prime}$ & 0.3461 & 0.3325 \\
& $\mathrm{Y}_{\beta \beta}^{\prime}$ & 0.8509 & 0.7712 \\
& $\mathrm{Y}_{\mathrm{r}}^{\prime}-\left(\mathrm{m}^{\prime}+\mathrm{m}_{\mathrm{x}}^{\prime}\right)$ & -0.1610 & -0.1891 \\
& $\mathrm{Y}_{\mathrm{rr}}^{\prime}$ & -0.0001 & -0.0024 \\
& $\mathrm{Y}_{\beta \mathrm{rr}}^{\prime}$ & 0.8351 & 0.6456 \\
& $\mathrm{Y}_{\beta \beta \mathrm{r}}^{\prime}$ & -0.3442 & -0.2890 \\
& $\mathrm{~N}_{\beta}^{\prime}$ & 0.1247 & 0.1148 \\
& $\mathrm{~N}_{\beta}^{\prime}$ & -0.0687 & -0.0380 \\
$\mathrm{~N}_{\mathrm{r}}^{\prime}$ & -0.0518 & -0.0499 \\
$\mathrm{~N}_{\mathrm{rr}}^{\prime}$ & -0.0363 & -0.0270 \\
& $\mathrm{~N}_{\beta \mathrm{rr}}^{\prime}$ & -0.0520 & -0.0703 \\
$\mathrm{~N}_{\beta \beta \mathrm{r}}^{\prime}$ & -0.2877 & -0.3248 \\
\hline \multirow{5}{*}{ Interaction } & $1-\mathrm{t}_{\mathrm{R}}$ & 0.7158 & 0.7421 \\
& $\mathrm{a}_{\mathrm{H}}$ & 0.3077 & 0.5311 \\
& $\mathrm{x}_{\mathrm{H}}^{\prime}$ & -1.4767 & -0.9638 \\
& $\mathrm{w}_{\mathrm{P} 0}$ & 0.2462 & 0.2929 \\
$\mathrm{w}_{\mathrm{R} 0}$ & 0.3175 & 0.4063 \\
$\varepsilon$ & 0.9053 & 0.8396 \\
& $\gamma$ & 0.4265 & 0.3112 \\
\hline
\end{tabular}

\subsection{Maneuverability Evaluation}

\subsubsection{Maneuverability Evaluation Conditions}

To evaluate the ship's performance, a maneuvering trial must be performed on both the port and starboard sides under the conditions specified below [1]:

1. deep, unrestricted water

2. calm environment

3. full load (summer load line draught, even keel condition)

4. steady approach at the test speed

However, unlike the simulation performed using the empirical formula, it was not possible to perfectly match the above conditions during the sea trial test due to unavoidable circumstances in the field. Therefore, we approximated the test conditions to the above specifications to the best of our ability. The difference in external force conditions may affect the verification result to some extent, but because the basic purpose of this study is to verify the validity of the modified empirical formula, we have decided to set aside such a difference for the present study. Table 6 shows the conditions for the actual test and the simulation of the target trawler. 
Table 6. Maneuverability evaluation conditions.

\begin{tabular}{ccccc}
\hline & \multicolumn{2}{c}{ Turning Motion } & \multicolumn{2}{c}{ 10/10 Zigzag Test } \\
\hline & Sea Trial Test & Simulations & Sea Trial Test & Simulations \\
\hline \multirow{2}{*}{ Wind direction (Relative) and Speed } & PORT: $205^{\circ}, 3.8 \mathrm{~m} / \mathrm{s}$ & calm & $341^{\circ}, 7.0 \mathrm{~m} / \mathrm{s}$ & calm \\
& STBD: $206^{\circ}, 4.1 \mathrm{~m} / \mathrm{s}$ & h/d $>6$ & $\sim 130 \mathrm{~m}$ & $\mathrm{~h} / \mathrm{d}>6$ \\
Water depth & $\sim 130 \mathrm{~m}$ & FWD: 5.3 & FWD: 5.18 & FWD: 5.3 \\
Ship draft $(\mathrm{m})$ & FWD: 5.18 & AFT: 5.3 & AFT: 5.28 & AFT: 5.3 \\
& AFT: 5.28 & PORT: 14.04 & 14.81 & 14.04 \\
Test speed $(\mathrm{kts})$ & PORT: 14.2 & STBD: 14.04 & & \\
& STBD: 14.52 & &
\end{tabular}

\subsubsection{Turning Motion Test}

As shown in Table 7 and Figure 7, the simulation results from Kijima et al. (1990) empirical formula and from the modified empirical formula satisfy the IMO maneuverability criteria. Kijima et al. (1990) empirical formula generated an estimation error of 0.5L for mean advance and 1.2L for mean tactical diameter. The modified empirical formula only generated an error for mean tactical diameter of size $0.1 \mathrm{~L}$. In addition, as shown in Figure 5, the absolute size of the trajectory was larger in Kijima et al. (1990) formula than in the modified formula.

Table 7. Quantitative comparison of the turning motion test results of the target trawler.

\begin{tabular}{llcclc}
\hline & Sea Trial Test & $\begin{array}{c}\text { Kijima et al. } \\
(\mathbf{1 9 9 0 )} \text { Formula }\end{array}$ & $\begin{array}{c}\text { Modified } \\
\text { Formula }\end{array}$ & IMO Criteria \\
\hline \multirow{5}{*}{ Advance (m) } & PORT & $241(2.8 \mathrm{~L})$ & $272(3.2 \mathrm{~L})$ & $224(2.6 \mathrm{~L})$ & \\
& STBD & $212(2.5 \mathrm{~L})$ & $277(3.3 \mathrm{~L})$ & $229(2.7 \mathrm{~L})$ & $(4.5 \mathrm{~L})$ \\
& Mean & $227(2.7 \mathrm{~L})$ & $275(3.2 \mathrm{~L})$ & $227(2.7 \mathrm{~L})$ & \\
\multirow{5}{*}{ Tac. Dia. (m) } & PORT & $225(2.6 \mathrm{~L})$ & $330(3.9 \mathrm{~L})$ & $250(2.9 \mathrm{~L})$ & \\
& STBD & $245(2.9 \mathrm{~L})$ & $343(4.0 \mathrm{~L})$ & $260(3.0 \mathrm{~L})$ & $(5.0 \mathrm{~L})$ \\
& Mean & 235 (2.8L) & $337(4.0 \mathrm{~L})$ & $255(3.0 \mathrm{~L})$ & \\
\hline
\end{tabular}

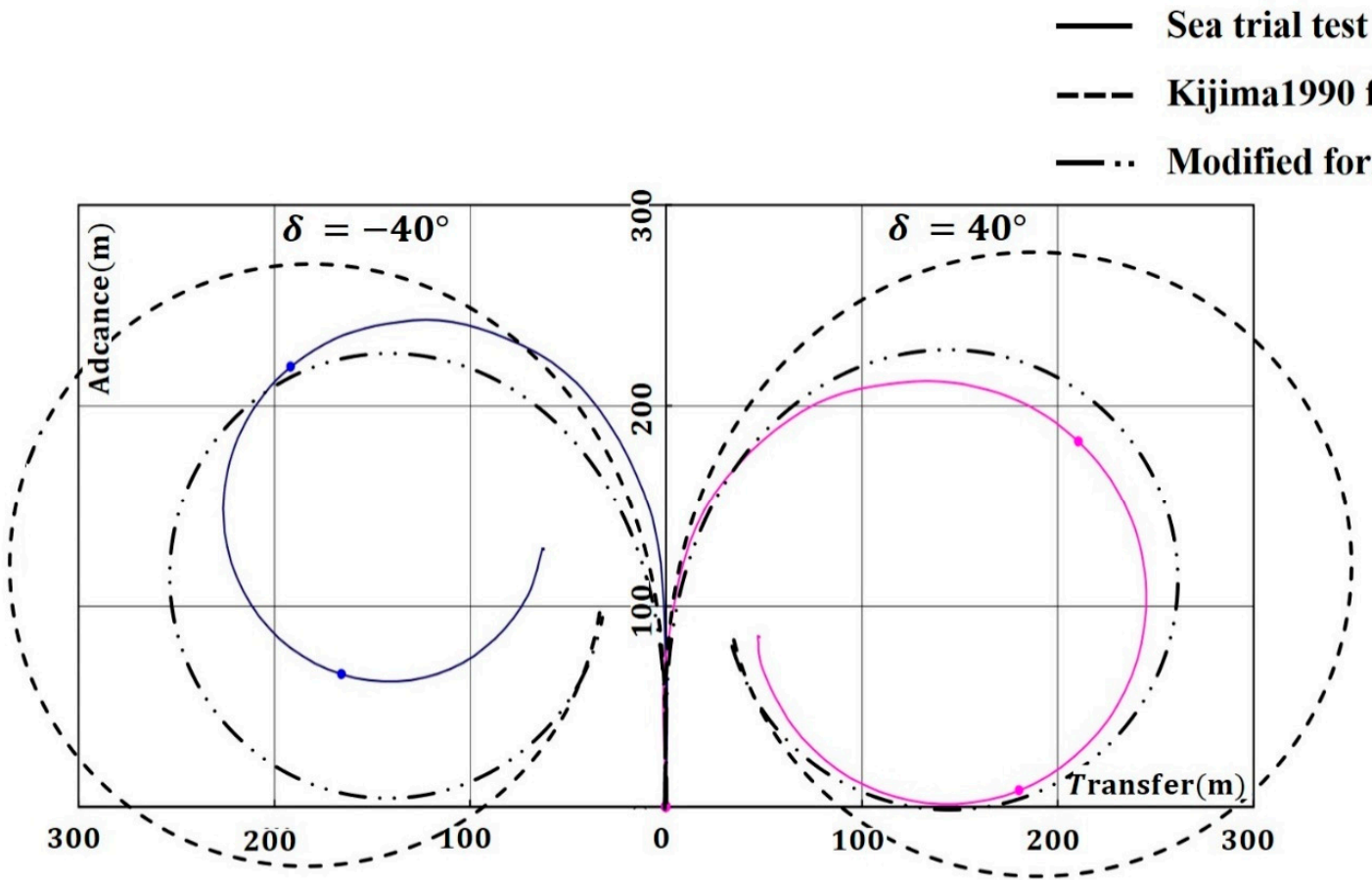

Figure 7. Comparison of the turning motion test results of the target trawler. 
As was mentioned in Section 3.3.1, since the effect of external force was considered in the sea trial test, the shape of the turning trajectory of the port and starboard sides was slightly different than the simulation result. This can be explained by considering and analyzing the effect of wind described in Table 6. At the time of the sea trial test, the target trawler turned when the wind was blowing from the relative bearing of 205-206 ${ }^{\circ}$ or the port side of its stern. At that moment, until the turn began, the influence of the wind blowing from the port acted to obstruct the turn. As a result, the advance tended to be slightly longer in this instance compared to turning to the starboard side. From the moment the turn began, the wind blowing from the port side of the ship's stern assisted with the turn, which led to a faster turn compared to a turn to the starboard side (Figure 7).

Table 8 and Figure 8 demonstrate the change in ship speed until steady turning occurred during the turning motion of the target trawler. In all three cases, the final speed was reduced when compared with the initial speed. This is due to the drag generated from the rudder plate and the drag generated around the hull during the turning motion. It is common knowledge that such reduction in the initial speed can be $\sim 30-40 \%$ for general ships and as much as 70-80\% for VLCC [27].

Table 8. Comparison of the speed deceleration rate during the turning motion for the target trawler.

\begin{tabular}{|c|c|c|c|c|c|c|}
\hline \multirow[b]{3}{*}{ Rudder angle $(\delta)$} & \multicolumn{6}{|c|}{ Turning Motion } \\
\hline & \multicolumn{2}{|c|}{ Sea Trial Test } & \multicolumn{2}{|c|}{$\begin{array}{l}\text { Kijima et al. } \\
\text { (1990) Formula }\end{array}$} & \multicolumn{2}{|c|}{ Modified Formula } \\
\hline & -40 & +40 & -40 & +40 & -40 & +40 \\
\hline Initial speed (kts) & 14.2 & 14.52 & 14.04 & 14.04 & 14.04 & 14.04 \\
\hline Final speed (kts) & 5.29 & 6.22 & 5.93 & 6.12 & 4.56 & 4.73 \\
\hline Speed reduction rate $(\%)$ & 62.7 & 57.2 & 57.8 & 56.4 & 67.5 & 66.2 \\
\hline
\end{tabular}
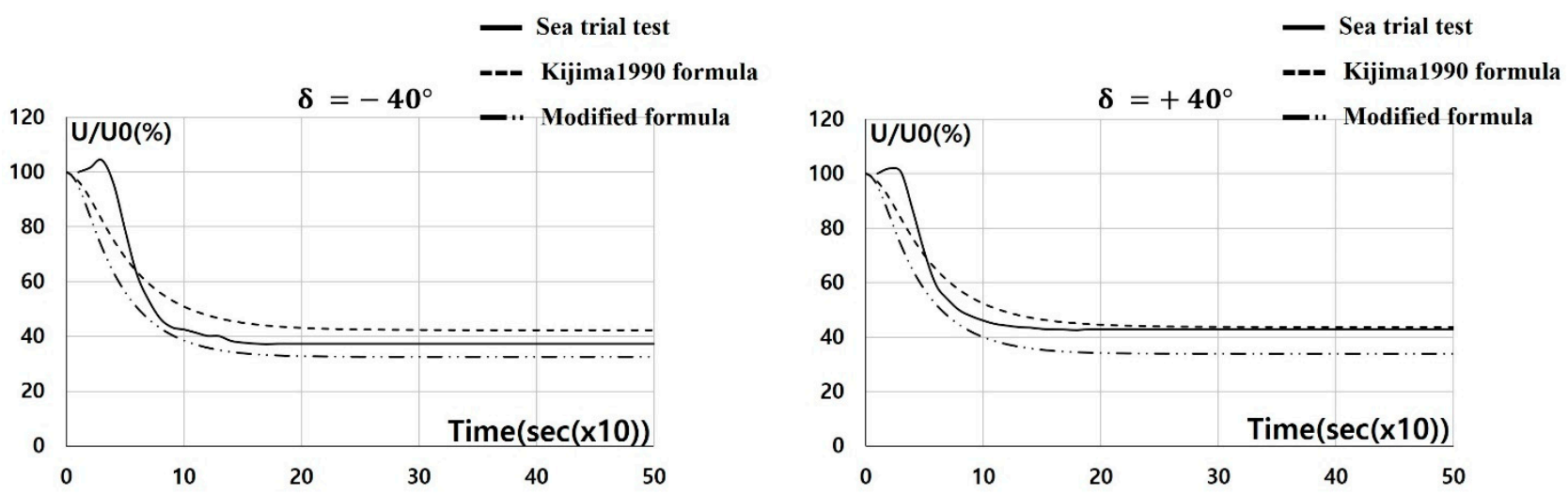

Figure 8. Comparison of the speed deceleration rate during the turning motion of the target trawler (where $U$ is the speed for each section and U0 is the initial speed).

In Table 8, the deceleration rate of the target trawler estimated by Kijima et al. (1990) empirical formula was $57.1 \%$, and thus, was lower than the observed average of $60 \%$ from both port and starboard sides by 2.9 percentage points. The modified empirical formula resulted in an average of $66.9 \%$, or 6.9 percentage points higher than the observed average. Quantitatively, these results indicate that the results of Kijima et al. (1990) empirical formula are closer to the actual test results. However, when evaluating the section from 0 - to 100-s mark in Figure 8, the qualitative results from the modified empirical formula demonstrate a trend that resembles the sea trial test results better. That is, the sea trial test and the modified empirical formula rapidly drop in the section from 0- to 100-s mark to reach the final speed, whereas Kijima et al. (1990) empirical formula produces a more gradual change. 
The $60 \%$ deceleration rate during the sea trial test of the target trawler is far off the general merchant ships range and is close to the range associated with VLCC. We surmise that the following two forces were in action here: the drag force generated from the large rudder area ratio-one of the characteristics of the fishing vessel-and the component of drag force generated from the hull specification L/B-similar to the VLCC. A detailed study on this result will be performed in the future [10].

\subsection{3. $10 / 10$ Zigzag Test}

The 10/10 zigzag test results of the target trawler are shown in Table 9 and Figure 9. Prior to the analysis, the target trawler had a length-speed ratio (L/V; LBP [m]/Speed $[\mathrm{m} / \mathrm{s}])$ of $11.1 \mathrm{~s}$ [1], and the first overshoot angle exceeded the IMO Criteria $10.55^{\circ}$ by $7.55^{\circ}$. However, since the target trawler is not a ship subject to the IMO standards, and the purpose of this study is to check the validity of the modified empirical formula and to improve the estimation accuracy, a study that analyzes the sea trial test results alone is excluded.

Table 9. Comparison of the $10 / 10$ zigzag test results for the target trawler.

\begin{tabular}{|c|c|c|c|c|}
\hline & Sea Trial Test & $\begin{array}{l}\text { Kijima et al. } \\
\text { (1990) Formula }\end{array}$ & Modified Formula & IMO Criteria \\
\hline Initial course $\left(^{\circ}\right)$ & 60 & 60 & 60 & \\
\hline Initial speed $(\mathrm{kts}[\mathrm{m} / \mathrm{s}])$ & $14.81[7.65]$ & $14.04[7.22]$ & $14.04[7.22]$ & \\
\hline $\mathrm{L} / \mathrm{V}(\mathrm{s})$ & 11.1 & 11.8 & 11.8 & \\
\hline 1st over shoot angle $\left(^{\circ}\right)$ & 18.1 & 4.6 & 10.7 & $(5+1 / 2(\mathrm{~L} / \mathrm{V}))$ \\
\hline 2nd over shoot angle $\left(^{\circ}\right)$ & 18.4 & 5.0 & 8.4 & $(17.5+0.75(\mathrm{~L} / \mathrm{V}))$ \\
\hline
\end{tabular}

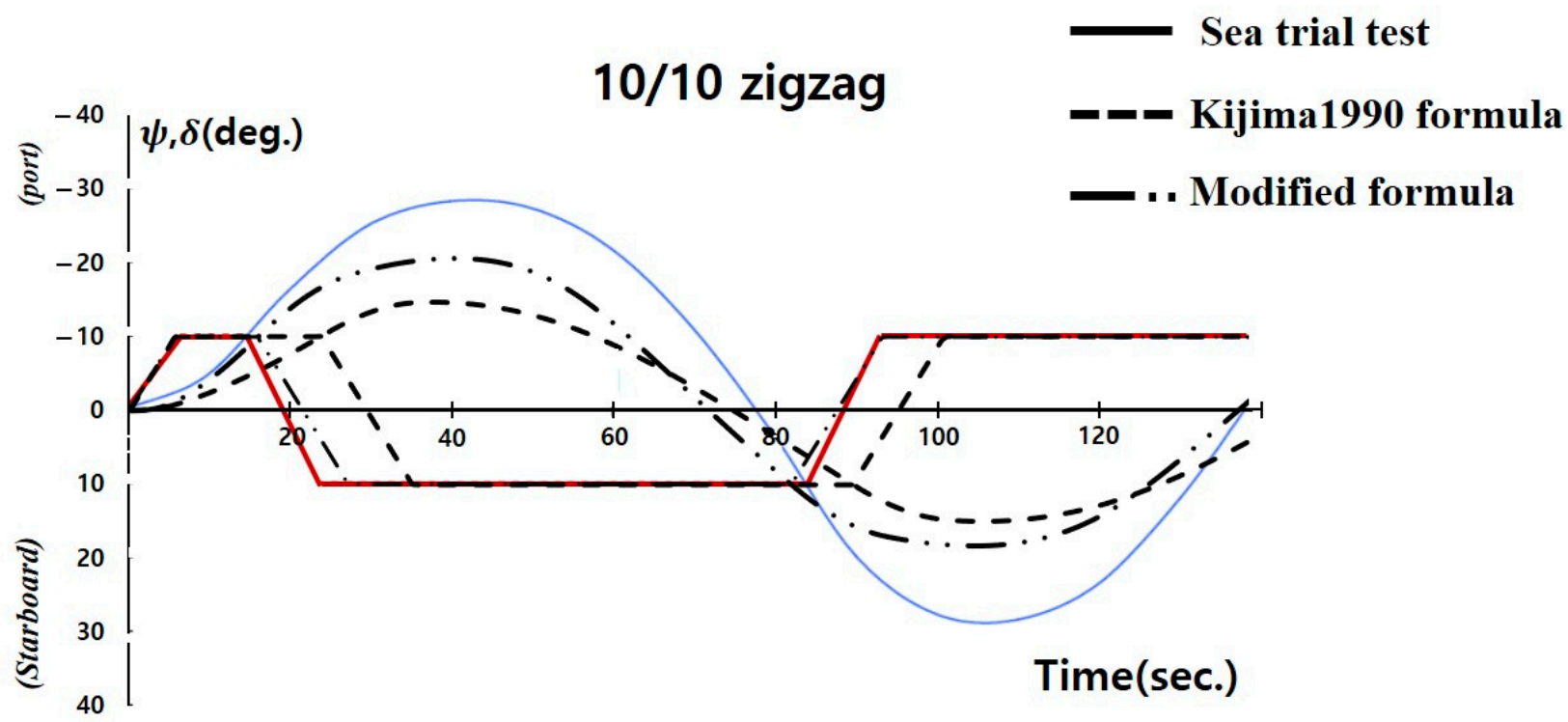

Figure 9. Comparison of the 10/10 zigzag test results for the target trawler.

In the case of the first overshoot angle, the results from the sea trial test, modified empirical formula, and Kijima et al. (1990) empirical formula were $18.1^{\circ}, 10.7^{\circ}$, and $4.6^{\circ}$, respectively. Concerning the results of the two empirical formulas, the modified empirical formula was able to approximate the sea trial test result better. For the second overshoot angle, the corresponding results from the sea trial test, modified empirical formula, and Kijima et al. (1990) empirical formula were $18.4^{\circ}, 8.4^{\circ}$, and $5.0^{\circ}$, respectively. The results of the modified empirical formula were slightly closer to the experimental test results than those of Kijima et al. (1990) empirical formula.

The absolute value of the overshoot angle was slightly different between the sea trial test and the two empirical formulas. This reflects the unique hull form characteristics of the 
target trawler. Various factors contribute to the maintenance of a vessel's course-keeping qualities, and the rudder area ratio plays an important part. The larger the rudder, the better the rudder effect. However, a larger rudder has the disadvantage in terms of decreased speed due to resistance. In the case of a fishing vessel's, the rudder area ratio is generally larger than that of merchant ships' because it requires quick maneuverability to track fish. The rudder area ratio is expressed as the ratio of the rudder area to the longitudinal cross-sectional area of the hull below the water line. In the maximum level of draft, the ratio is typically $1 / 60$ to $1 / 70$ for general merchant ships, $1 / 35$ to $1 / 40$ for fishing vessels, and $1 / 30$ to $1 / 50$ for military vessels [27].

\section{Conclusions}

Due to the lack of research on estimating the maneuverability for the hull forms of fishing vessels, the empirical formula originally developed for merchant ships' hull form is being used even for fishing vessels. Since the empirical formula was derived by regression analysis of the model test results of merchant ships' hull form, the process led to estimation errors when applied to the hull form of fishing vessels with different hull form characteristics.

With these in mind, we derived a modified empirical formula by adding the hull form parameters of fishing vessels' using Kijima et al. (1990) empirical formula, which had originally been developed for merchant ships' hull form. Using the modified empirical formula, this study estimated the maneuverability of the trawl fishing vessel hull form and compared the result with that from the sea trial test.

The turning motion test revealed that the estimation errors of Kijima et al. (1990) empirical formula were $0.5 \mathrm{~L}$ for mean advance and 1.2L for mean tactical diameter when compared to the results from the sea trial test, whereas the modified empirical formula only generated an error of $0.1 \mathrm{~L}$ in mean tactical diameter. This finding suggests that the latter quantitatively and qualitatively produces better approximation.

From the 10/10 zigzag test, we also observed that Kijima et al. (1990) and modified empirical formulas generated estimation errors of $13.5^{\circ}$ and $7.4^{\circ}$ for the first overshoot angle, respectively; the corresponding values for the second overshoot angle were $13.4^{\circ}$ and $10.0^{\circ}$, respectively. These results also confirmed that the modified empirical formula offered better approximation to the results from the sea trial test both quantitatively and qualitatively.

The present study also aided in understanding how much the unique characteristics of hull form parameters associated with each vessel could impact the derivation process for empirical formulas. Moreover, it could also be seen that the characteristics of rudders, propellers, and other auxiliary components may engender varying motion characteristics of ships even when they are of the same type and have similar hull forms to one another.

We verified that modifying existing empirical formulas originally developed for hull forms of merchant ships by simply adding the hull form parameters of fishing vessels can improve their estimation results. It was also confirmed that even a slight difference in the characteristics of hulls, propellers, or rudders can introduce differing motion characteristics, thus leading to estimation errors-even when the ships of interest are of the same type. These results reaffirm the need for an empirical formula tailored to the hull forms of fishing vessels, as well as the need for a process for systematically updating previously developed empirical formulas with additional modifications.

As the present study focused on validating the performance of the modified empirical formula, we intend to build upon the results obtained here to conduct more detailed studies on the bank effect and ship-to-ship [28,29] comparisons of fishing vessels' hull forms in the future. Such a study would serve as a good indicator for those who operate fishing vessels and play an important role in analyzing maritime accidents should they occur. 
Author Contributions: Conceptualization, S.-H.K.; methodology, S.-H.K.; software, C.-K.L.; analysis, S.-H.K.; writing—original draft preparation, S.-H.K.; writing-reviewing and editing, C.-K.L.; supervision, S.-H.K. All authors have read and agreed to the published version of the manuscript.

Funding: This research received no external funding.

Institutional Review Board Statement: Not applicable.

Informed Consent Statement: Not applicable.

Data Availability Statement: The data used to support the findings of this study are available from the corresponding author upon request.

Acknowledgments: This research was supported by the 'Development of Autonomous Ship Technology (20200615) 'funded by the Ministry of Oceans and Fisheries (MOF, Korea).

Conflicts of Interest: The authors declare no conflict of interest.

\section{Nomenclature}

\begin{tabular}{|c|c|}
\hline$A_{R}$ & rudder area \\
\hline$a_{H}$ & rudder force increase factor \\
\hline $\mathrm{C}$ & coefficient for starboard and port rudder \\
\hline $\mathrm{C}_{\mathrm{N}}$ & rudder normal force gradient coefficient \\
\hline $\mathrm{C}_{\mathrm{tP}}$ & constants \\
\hline$C_{1}, C_{2}, C_{3}$ & constants \\
\hline $\mathrm{D}_{\mathrm{P}}$ & propeller diameter \\
\hline $\mathrm{F}_{\mathrm{N}}^{\prime}$ & normal force acting on the rudder/non-dimensionalized \\
\hline $\mathrm{h}_{\mathrm{R}}$ & rudder height \\
\hline $\mathrm{I}_{\mathrm{zZ}}^{\prime} \mathrm{i}_{\mathrm{zZ}}^{\prime}$ & $\begin{array}{l}\text { inertia moment of } z \text { axis direction, added inertia moment/non-dimensionalized } \\
\text { advance coefficient }\end{array}$ \\
\hline $\mathrm{K}_{\mathrm{R}}$ & aspect ratio of the rudder \\
\hline $\mathrm{K}_{\mathrm{T}}$ & thrust coefficient \\
\hline $\mathrm{m}^{\prime}, \mathrm{m}_{\mathrm{x}}^{\prime}, \mathrm{m}_{\mathrm{y}}^{\prime}$ & $\begin{array}{l}\text { mass of ship, added mass of } x \text { axis direction, added mass of } \\
y \text { axis direction/non-dimensionalized }\end{array}$ \\
\hline $\mathrm{n}$ & propeller revolution \\
\hline $\mathrm{nP}$ & propeller revolution \\
\hline S & slip ratio \\
\hline$t_{\mathrm{P} 0}$ & thrust deduction coefficient in straight forward moving direction \\
\hline$t_{R}$ & steering deduction factor \\
\hline $\mathrm{U}, \beta, \delta$ & resultant velocity, drift angle, rudder angle \\
\hline $\mathrm{U}_{\mathrm{R}}$ & effective rudder inflow speed \\
\hline $\mathrm{u}, \mathrm{v}, \mathrm{r}$ & velocity components at the center of gravity of ship and yaw rate about $z$ axis \\
\hline $\mathrm{w}_{\mathrm{P}}$ & effective wake coefficient at the position of the propeller \\
\hline $\mathrm{w}_{\mathrm{R}}$ & effective wake coefficient at the position of the rudder \\
\hline $\mathrm{w}_{\mathrm{P} 0}$ & $\begin{array}{l}\text { effective wake coefficient at the position of the propeller in } \\
\text { straight forward moving direction }\end{array}$ \\
\hline $\mathrm{w}_{\mathrm{R} 0}$ & $\begin{array}{l}\text { effective wake coefficient at the position of the rudder in } \\
\text { straight forward moving direction }\end{array}$ \\
\hline $\mathrm{x}_{\mathrm{H}}^{\prime}$ & distance between C.G and the center of additional lateral force/non-dimensionalized \\
\hline$x_{R}^{\prime}$ & longitudinal coordinate of the position of the rudder/non-dimensionalized \\
\hline$a_{R}$ & effective rudder inflow angle \\
\hline$\beta_{\mathrm{R}}^{\prime}$ & effective inflow angle to the rudder in maneuvering motion/non-dimensionalized \\
\hline$\delta$ & rudder angle \\
\hline $\mathrm{k}$ & $2 \mathrm{~d} / \mathrm{L}$ \\
\hline$\gamma$ & flow straightening coefficient \\
\hline $1-w_{P}$ & effective wake fraction at the position of the propeller \\
\hline$\cdot(\operatorname{dot})$ & derivative with respect to time \\
\hline ' (prime) & non-dimensionalized quantity \\
\hline
\end{tabular}




\section{References}

1. IMO MSC 76/23. "Standards for Ship Manoeuvrability" Report of the Maritime Safety Committee on Its 76th Session-Annex 6; Resolution MSC 137(76); IMO: London, UK, 2002; pp. 1-6.

2. Yoshimura, Y.; Ma, N.; Suzuki, S.; Kajiwara, Y. Manoeuvring Performance of the Fishing vessel Modified by a Bulge. J. Soc. Nav. Archit. Jpn. 2002, 192, 37-46. [CrossRef]

3. Yoshimura, Y.; Ma, N. Manoeuvring Prediction of Fishing vessel. In MARSIM 03'Conference Proceedings; The Society of Naval Architects of Japan, Japan Institute of Navigation and International Marine Simulator Forum: Kanazawa, Japan, 2003; RC-29-1-10.

4. Obreja, D.; Nabergoj, R.; Crudu, L.; Păcuraru-Popoiu, S. Identification of hydrodynamic coefficients for manoeuvring simulation model of a fishing vessel. Ocean Eng. 2010, 37, 678-687. [CrossRef]

5. Lee, C.K.; Kim, S.H.; Lee, J.G.; Lee, S.M.; Kim, M.S. A Study on the Characteristics of Manoeuvrability of Fishing Vessel. J. Korean Soc. Fish. Ocean Technol. 2018, 54, 239-245. [CrossRef]

6. Lee, C.K.; Kim, S.H.; Yim, J.B.; Lee, S.M. Study on the Maneuvering Characteristics of a Fishing Vessel in Shallow Water. Nav. Eng. J. 2019, 131-132, 95-104.

7. Lee, C.K.; Kim, S.H.; Lee, S.M.; Yim, J.B. Study on the Manoeuvring prediction of a fishing vessel. Nav. Eng. J. 2019, 131-134, 101-109.

8. Kim, S.H.; Lee, C.K.; Lee, S.M. Estimation of Maneuverability of Fishing Vessel Considering Hull-Form Characteristics. J. Mar. Sci. Eng. 2021, 9, 569. [CrossRef]

9. Yoshimura, Y.; Yasukawa, H. Introduction of MMG Standard Method for Ship Maneuvering Predictions. J. Mar. Sci. Technol. 2015, 20, 37-52. [CrossRef]

10. Kim, S.H. A Study on the Improvement of the Accuracy of Fishing Vessels Manoeuvrability Prediction. Ph.D. Thesis, Korea Maritime and Ocean University, Busan, Korea, 2020.

11. Yoshimura, Y.; Masumoto, Y. Hydrodynamic Force with Medium High Speed Merchant Ships Including Fishing Vessels and Investigation into a Manoeuvring Prediction Method. J. Jpn. Soc. Nav. Archit. Ocean Eng. 2011, 14, 63-73. [CrossRef]

12. Lee, M.K.; Park, Y.S. Collision Prevention Algorithm for Fishing Vessels Using WAVE Communication. J. Mar. Sci. Eng. 2020, 8, 115. [CrossRef]

13. Jung, C.H. A Study on the Improvement of Safety by Accidents Analysis of Fishing Vessels. J. Fish. Mar. Sci. Educ. 2018, 30, 179-186.

14. Kim, S.H.; Kim, H.S.; Lee, Y.W. The Causes and Counterplan for Marine Casualties of Fishing Vessels According to the Fishing Types. J. Korean Soc. Fish. Ocean Technol. 2020, 56, 246-257. [CrossRef]

15. Lee, M.K.; Park, Y.S.; Park, S.W.; Lee, E.K.; Park, M.J.; Kim, N.E. Application of Collision Warning Algorithm Alarm in Fishing Vessel's Waterway. Appl. Sci. 2021, 11, 4479. [CrossRef]

16. Kijima, K.; Katsuno, T.; Nakiri, Y.; Furukawa, Y. On the Manoeuvring Performance of a Ship with the Parameter of Loading Condition. J. Soc. Nav. Archit. Jpn. 1990, 168, 141-148. [CrossRef]

17. Result of Sea Trial Test; Dae Sun Shipbuilding \& Engineering Co., Ltd.: Busan, Korea, 2020.

18. Ogawa, A.; Koyama, T.; Kijima, K. MMG report-I, on the Mathematical Model of Ship Manoeuvring. Bull. Soc. Nav. Archit. Jpn. 1977, 575, 22-28.

19. Kobayashi, E.; Kagemoto, H.; Furukawa, Y. Mathematical Models of Ship Manoeuvring Motion; 2nd symposium. J. Soc. Nav. Arch. 1995, 1995, 23-84.

20. Kijima, K.; Nakiri, Y. Approximate Expression for Hydrodynamic Derivatives of Ship Manoeuvring Motion Taking into Account of the Effect of Stern Shape. Trans. West Jpn. Soc. Nav. Arch. 1999, 98, 67-77.

21. Kijima, K.; Nakiri, Y. On the Practical Prediction Method for Ship Manoeuvring Characteristics. Trans. West Jpn. Soc. Nav. Arch. 2003, 105, 21-31.

22. Kim, K.Y. Manoeuverabilities of the M.S “SAEBADA”. J. Korean Soc. Fish. Ocean Technol. 1979, 12, $209-215$.

23. Kim, M.S.; Shin, H.O.; Kang, K.M.; Kim, M.S. Variation of Turning Circle by the Rudder Angle and the Ship's Speed. J. Korean Soc. Fish. Ocean Technol. 2005, 41, 156-164. [CrossRef]

24. Ahn, Y.H.; Park, M.H.; Choi, C.M.; Chung, Y.J. A Study on the Maneuverabilities of the Training ship M.S. A-RA. J. Korean Soc. Fish. Ocean Technol. 2001, 37, 275-284.

25. An, Y.S.; Kang, I.K.; Kim, H.S.; Kim, J.C.; Kim, M.S.; Jo, H.J.; Lee, C.K. A Study on the Manoeuvrability of T/S SAEBADA by Real sea trials. J. Korean Soc. Fish. Ocean Technol. 2005, 41, 289-295. [CrossRef]

26. Kim, M.S.; Shin, H.I.; Kim, J.H.; Kang, I.K. A Study on the Maneuverabilities of the T.S KAYA. J. Fish. Mar. Sci. Educ. 2009, 21, 59-67.

27. Yoon, J.D. Theory and Practice of Ship Manoeuvring; Sejong Publishing Co.: Busan, Korea, 2019.

28. Huang, J.; Xu, C.; Xin, P.; Zhou, X.; Sutulo, S.; Soares, C.G. A Fast Algorithm for the Prediction of Ship-Bank Interaction in Shallow Water. J. Mar. Sci. Eng. 2020, 8, 927. [CrossRef]

29. Hong, C.B.; Lee, S.M. A Study on Barge-Bank Interaction Forces Considering the Reflected Waves. J. Mar. Sci. Eng. 2020, 8, 451. [CrossRef] 